\title{
Review of the features of augmented reality application in the training of operators and maintenance staff
}

\author{
S V Byvaltsev ${ }^{1,2}$ \\ ${ }^{1}$ Ural Federal University named after the First President of Russia B N Yeltsin, 19, \\ Mira Street, Ekaterinburg, 620002, Russia \\ ${ }^{2}$ Institute of Engineering Science, Ural Branch of the Russian Academy of Sciences, \\ 34, Komsomolskaya Street, Ekaterinburg, 620049, Russia \\ E-mail: s_ikar@mail.ru
}

\begin{abstract}
An overview of the use of augmented reality technology used to improve the training efficiency of operators and service personnel in the industry is presented. When considering the issues of building augmented reality systems, it was noted that in addition to technological issues, it is also essential to pay increased attention to the social aspect, especially if it is intended to apply augmented reality technology in multiplayer mode. A common environment in the interaction of several participants can disrupt the sense of identity of users, as well as potentially threaten the feeling of personal space and the sensation of physical objects. It is necessary to take into account the cognitive load theory and the schematic theoretical model of concreteness fading. The advantage of using augmented reality is to reduce human errors and improve the quality of training. For the use of augmented reality in the absence of a reliable network connection and the availability of only short communication sessions, the use of special tickets is proposed.
\end{abstract}

\section{Introduction}

The augmented reality is penetrating more and more into industry and education every year. The Ministry of Digital Development, Communications and Mass Media of the Russian Federation has developed the Roadmap for the development of 'through' digital technology 'Technology of virtual and augmented reality' [1].

The mixing of physical and digital worlds defines the combination of real and virtual environments and it is a part of the reality/virtual continuum (RVC) [2], [3]. The RVC describes the interactions between reality and virtuality. In RVC, augmented reality (AR) is the reflection of virtual objects in the context of the real world. Modern AR solutions on portable devices use an image from a real device and combine it with virtual content. These solutions have been mass-produced for a long time as head-mounted devices, for example, Microsoft HoloLens 2 [4], Google Glass Enterprise Edition 2 [5], Meta 2 [6]. Modern AR applications also include tactile feedback and spatial sound [7], [8].

\section{Features of $A R$ application in training}

The application of AR to increase the efficiency of operators and maintenance staff is an undoubted advantage, but it is necessary to develop special software products with support of AR and to teach users how to use this technology. The amount of information provided through AR should be dosed. as operators can get used to hints of system and desire to solve problems independently and even 
impossibility to carry out the same actions without AR application will decrease. For this purpose, it is offered to reduce gradually a stream of the new information as it is possible that really important one will be missed. In addition, it is necessary to remove the insignificant or irrelevant information out of the executed process.

It is important to remember that people have limited working memory capacity [9], [10]. There are three types of cognitive load in the learning process: 1) intrinsic cognitive load, determined by the complexity of the learning task itself, 2) extraneous cognitive load associated with conscious, constructive processes used to construct mental representations and not conducive to learning, 3) appropriate cognitive load. If the memory capacity is fully utilized in internal and external processes, there will be no remaining cognitive resources for learning and learning will be difficult. According to the Four-component Instructional Design (4C/ID) mode of learning [11], early learning tasks should include a lower intrinsic cognitive load from the interactivity of elements, and as tasks become more complex, the extraneous load should decrease when moving to more complex material.

According to the schematic theoretical model of concreteness fading [12], the process of operator training should be effectively conducted in three stages. At the first stage, training is provided on specific examples, when it is easier for the operator to interpret ambiguous abstract views in terms of well-understood specific objects, as well as to use the advantages of embodied knowledge, which gives experience with physical and perceptual processes that are limited and give the right conclusions. According to an embodied theory of cognition [13], [14], high-level cognitive processes stem from action and perception. At this stage, understanding abstract symbols requires reflecting these symbols on a bodily experience or a representation of these experiences. The concrete stage enables learners to acquire a store of images that can be used when abstract symbols are forgotten or disconnected from the underlying concept. In addition, the operator remembers a set of images, symbols and gestures that will be used in the AR metaphor when abstract symbols relate to real objects. After mastering the abstract concept in solving new problems, the operator will rely on this set of attributes [15]. At the other two stages, there is a transition from real physical representation to graphic schemes and models, and then to ordinary abstract symbols.

This point requires further research, because according to [16] the transition from abstract to concrete can sometimes improve the learning efficiency.

Thus, when training operators, AR software must adapt to the operator's accumulated experience. The transition is made from pointing out the sequence of all necessary steps for performing a specific operation to controlling the correctness of actions and fixing the very fact of execution of embedded instructions.

\section{Social and technical aspects of AR application}

At the building AR, the technical aspects of designing the AR environment are most often investigated. Only recently it has been noted that the social aspect of the application of AR has to be taken into account. AR users are developing a sense of interconnection and psychological belonging to virtual artifacts in AR environment develops more, than in the usual virtual environment. A common environment in the interaction of several participants may disturb the sense of identity of users, as well as potentially threaten the sense of personal space and the sense of physical objects [17], [18]. There is a certain difference in the estimation of perception when using augmented reality glasses and the hand-held device [19]. To transfer feedback to the AR system it is possible to use sensors installed on the body. However, some actions are easier to perform in the street than in a public place, because some gestures are simply not permitted there [20]. Also note that gestures and movements of the operator may not be related to the AR control process, but to other work, maintenance of the system or random movements.

Also, while using AR it is possible to feel physiological discomfort when personal space is disturbed [21]. 
Besides, to increase efficiency of training it is important to raise level of user's perceived trust to AR system [22] and to visualize processes with application of habitual for the operator external environment, especially at remote control mode.

As it has already been noted, in the process of training to work with AR it is necessary to move from the virtual environment to the real world, when the operator is given only the necessary dosing information and his actions are controlled and checked for correctness. It is suggested to use multilevel scenarios of data display depending on qualification and type of staff. For example, to display only the current temperature, its graph in the near future, its extrapolation to the future, or only a message when it deviates from the expected value, etc.

In the same way, in order to present data, it is required to move from a real physical representation to an abstract one.

Nowadays AR is widely used directly for the learning process itself [23], [24]. In our opinion, it is more effective to apply AR for large and complex systems, in which it is necessary to provide reliability and stability through the abstract presentation of data to the operator in real time, overlaid on the natural environment [25].

The easiest way to analyze the external environment is to use the computer vision library OpenCV [26]. To bind physical objects, we suggest using markerless framework which does not imply the use of feducian markers [27] or even natural markers in the environment [28], [29]. At the same time there is a problem of adaptation of computer vision system to changes in external illumination [30]. Most often the image of equipment is processed through a calibrated camera by ARToolKit [31] or SLAM [32] framework, which can be replaced by a more advanced GLEAM [33]. It should be noted that it is important to try to eliminate the perceptional problem of incorrect depth interpretation of graphical objects overlaid on the real world [34], [35]. This is especially shown in stereoscopic systems, where it is required to provide 'translucent vision' or challenging X-ray visualization. For hand-held devices such problem is less actual [36].

The greatest effect from the application of AR can be achieved with the provision of joint activities and work that requires coordinated efforts. In this case, for multi-user AR especially actual becomes the social aspect considered earlier, and also safety and protection against extraneous intervention [37], [38].

An additional advantage of using AR is the reuse of the training software. If there is a change of operators and maintenance staff, there is no need to teach them all the knowledge and skills at once. They receive them directly from the AR system during application. The qualification requirements for users are considerably reduced, but the requirements for the AR system (software, databases and knowledge, rules and models) increase. Also, there are fewer human errors and it is possible to control the operator's actions in real time [39].

\section{The direction of further research}

Certain problems can represent possibility of operation AR without access to a network, in an offline mode, but designers of AR offer to use sessions of communication and special tickets for the industry [40].

Despite the difficulties with introduction AR in the industry the advanced manufacturers of automation equipment already offer ready decisions [41], [42].

In our opinion AR should be used for complex systems where it is necessary to exclude human errors. [43], [44].

It should be noted that AR is increasingly used not only for staff training but also for controlling industrial systems [45], [46] and applications [47], [48].

\section{Acknowledgements}

The author expresses his gratitude to the staff of the Department of Information Technologies and Design Automation of Ural Federal University and the staff of the Laboratory of System Modelling of 
the Institute of Engineering Science, Ural Branch of the Russian Academy of Sciences without valuable advice and critical comments of which it would be impossible to publish this study.

\section{References}

[1] The Roadmap for the development of 'through' digital technology 'Technology of virtual and augmented reality' Accessed at: https://digital.gov.ru/ru/documents/6654/ (accessed 04.03.2020)

[2] Milgram P and Kishino F 1994 IEICE Trans. Inf \& Syst. E77-D $121322-9$

[3] Milgram P, Takemura H, Utsumi A and Kishino F 1994 SPIE, Telemanipulator and Telepresence Technologies 2351 282-92

[4] Website of Microsoft HoloLens 2 Available at: https://www.microsoft.com/en-us/hololens/ (accessed 04.03.2020)

[5] Technical specifications of Google Glass Enterprise Edition 2 Available at: https://www.google.ru/glass/tech-specs/ (accessed 04.03.2020)

[6] The Meta 2 Development Kit Available at: https://www.schenker-tech.de/en/meta-2/ (accessed 04.03.2020)

[7] Goose S, Sudarsky S, Zhang X, and Navab N 2003 IEEE Pervasive Computing vol 2 issue 1 $65-70$

[8] Radu I and Schneider B 2019 Proc. of the 2019 CHI Conf. on Human Factors in Computing Systems (CHI '19) (New York: ACM) pp 544:1-544:12

[9] Sweller J, Merrienboer J J G and Paas F W C 1998 Educational Psychology Review vol 10 25196

[10] Baddeley A D 1983 Phil. Trans. R. Soc. Lond. B vol 3021110 311-24

[11] Merrienboer J J G and Sluijsmans D M A 2009 Educational Psychology Review 21(1) 55-66

[12] Fyfe E R, Neil N M, Son J Y and Goldstone R L 2014 Educational Psychology Review 26(1) 925

[13] Barsalou L W 2003 Language \& Cognitive Processes 18 513-62

[14] Lakoff G and Nunez R E 2000 Where mathematics comes from: how the embodied mind brings mathematics into being (New York: Basic Books) p 493

[15] Bruner J S 1966 Toward a theory of instruction (Cambridge: Belknap) p 192

[16] Johnson A M, Reisslein J and Reisslein M 2014 Computers \& Education 72 249-61

[17] Poretski L, Lanir J, Arazy O and Oded N 2019 Proc. of the 1st Workshop on Challenges Using Head-Mounted Displays in Shared and Social Spaces CHI'19 Extended Abstracts (Glasgow, Scotland UK) p 6

[18] Poretski L, Lanir J and Arazy O 2018 Proc. of the ACM on Human-Computer Interaction (PACMHCI) 2 CSCW (New York, USA) pp 142:1-24

[19] Koelle M, Kranz M and Möller A 2015 Proc. of the 17th Int. Conf. on Human-Computer Interaction with Mobile Devices and Services MobileHCI '15 362-72

[20] Williamson J R, Crossan A and Brewster S 2011 Proc of the 13th Int. Conf. on Multimodal Interfaces ICMI'11 361-8

[21] Wilcox L M, Allison R S, Elfassy S and Grelik C 2006 ACM Transactions on Applied Perception 34 412-28

[22] Haesler S, Kim K, Bruder G and Welch G 2018 IEEE Int. Symp. on Mixed and Augmented Reality Adjunct (ISMAR-Adjunct) pp 204-5

[23] Manoela S, Teichrieb V and Smith P 2019 Anais dos Workshops do VIII Congresso Brasileiro de Informática na Educação (WCBIE 2019) pp 1452-6

[24] Fite-Georgel P 2011 10th IEEE Int. Symp. on Mixed and Augmented Reality (ISMAR) (Basel Switzerland) pp 201-10

[25] Masood T and Egger J 2019 Robotics and Computer-Integrated Manufacturing 58 181-95

[26] OpenCV for Processing, by Greg Borenstein. A Processing library for the OpenCV computer vision library Available at: https://github.com/atduskgreg/opencv-processing (accessed 
04.03.2020)

[27] Fiala M 2005 Proc. IEEE Computer Society Conf. on Computer Vision and Pattern Recognition (CVPR) 2 590-6

[28] Gomes D L, de Paiva A C, Silva A C, Braz G, de Almeida J D S, de Araújo A S and Gattas M 2018 Computers in Industry 97 67-75

[29] Georgel P, Schroeder P, Benhimane S, Hinterstoisser S, Appel M and Navab N 2007 6th IEEE and ACM Int. Symp. on Mixed and Augmented Reality (Nara, Japan: IEEE) pp 111-5

[30] Grosch T, Eble T and Mueller S 2007. Proc. of the 2007 ACM symp. on Virtual reality software and technology (New York: ACM) pp 125-32

[31] Kato H and Billinghurst M 2004 3rd IEEE and ACM Int. Symp. on Mixed and Augmented Reality (ISMAR 2004) (Arlington VA USA: IEEE) p 305

[32] Tamaazousti M, Naudet-Collette S, Gay-Bellile V, Bourgeois S, Besbes B and Dhome M 2016 Multimedia Tools and Applications 75 9511-47

[33] Prakash S, Bahremand A, Nguyen L D and LiKamWa R 2019 Proc of the 17th Annual Int. Conf. on Mobile Systems, Applications, and Services (MobiSys'19) (New York: ACM) pp $142-54$

[34] Kruijff E, Swan J, and Feiner S 2010 Proc. of the 9th IEEE Int. Symp. on Mixed and Augmented Reality (ISMAR) (Los Alamitos, CA: IEEE) pp 3-12

[35] Kytö M, Makinen A, Häkkinen J and Oittinen P 2013 ACM Transactions on Applied Perception $1016: 1-21$

[36] Sailer C, Rudi D, Kurzhals K and Raubal M 2019 18th World Conf. on Mobile and Contextual Learning: Future Learning Through Experiences and Spaces (mLearn 2019) (Delft, Netherlands) pp 69-76

[37] Ruth K, Kohno T and Roesner F 2019 Proc. of 28th USENIX Security Symposium (Santa Clara, CA, USA: USENIX Association) pp 141-58

[38] Lebeck K, Kohno T and Roesner F 2019 Proc. of 20th Int. Workshop on Mobile Computing Systems and Applications (HotMobile '19) (New York: CM) pp 81-86

[39] Introducing Vuzix M4000 Smart Glasses at CES2020 Available at: https://youtu.be/ENUCXX2fz-c/ (accessed 04.03.2020)

[40] Website of Augmented Reality on Actemium Available at: https://www.actemium.nl/themas/augmented-reality/ (accessed 04.03.2020)

[41] About EcoStruxure Augmented Operator Advisor Available at: https://www.se.com/ww/en/product-range/64507-ecostruxure\%E2\%84\%A2-augmentedoperator-advisor/ (accessed 04.03.2020)

[42] Industrial Augmented reality with EcoStruxure ${ }^{\mathrm{TM}}$ Augmented Operator Advisor Available at: https://www.youtube.com/embed/LBolUiyUKyE/ (accessed 04.03.2020)

[43] Gimeno J, Casas S, Portales C and Fernandez M 2019 DYNA 94(2) 155-60

[44] Hofmann C, Staehr T, Cohen S, Stricker N, Haefner B and Lanza G 2019 Procedia Manufacturing 31 148-54

[45] Antonijević M, Sučić S and Keserica H 2018 Energies 11(3) 599:1-17

[46] Masood T and Egger J 2019 Robot. and Comput. Integr. Manuf. 58 181-95

[47] Kyeong-Beom P, Minseok K, Sung H, Choi J and Yeol L 2020 Robot. and Comput. Integr. Manuf. 63 101887:1-18

[48] Egger J and Masood T 2020 Computers \& Industrial Engineering 140 106-95 